\title{
Application of polymer-mesh device to remodel left ventricular-mitral valve apparatus in ischemic mitral regurgitation
}

\author{
Akihisa Kataoka, MD, PhD, ${ }^{a}$ Xin Zeng, MD, PhD, ${ }^{a}$ J. Luis Guerrero, BS, ${ }^{b}$ Adam Kozak, BS, \\ Gavin Braithwaite, $\mathrm{PhD},{ }^{\mathrm{c}}$ Robert A. Levine, $\mathrm{MD},{ }^{\mathrm{a}}$ Gus J. Vlahakes, $\mathrm{MD},{ }^{\mathrm{b}}$ and Judy Hung, $\mathrm{MD}^{\mathrm{a}}$
}

\section{ABSTRACT}

Objectives: Ischemic mitral regurgitation (IMR) results from ischemic left ventricular $(\mathrm{LV})$ distortion and remodeling, which displaces the papillary muscles and tethers the mitral valve leaflets apically. The aim of this experimental study was to examine efficacy of an adjustable novel polymer filled mesh (poly-mesh) device to reverse $\mathrm{LV}$ remodeling and reduce IMR.

Methods: Acute $(\mathrm{N}=8)$ and chronic ( 8 weeks; $\mathrm{N}=5$ ) sheep models of IMR were studied. IMR was produced by ligation of circumflex branches to create myocardial infarction. An adjustable poly-mesh device was attached to infarcted myocardium in acute and chronic IMR models and compared with untreated sham sheep. Two- and 3-dimensional echocardiography and hemodynamic measurements were performed at baseline, post IMR, and post poly-mesh (humanely killed).

Results: In acute models, moderate IMR developed in all sheep and decreased to trace/mild (vena contracta: $0.50 \pm 0.09 \mathrm{~cm}$ to $0.26 \pm 0.12 \mathrm{~cm} ; P<.01$ ) after polymesh. In chronic models, IMR decreased in all sheep after poly-mesh, and this reduction persisted over 8 weeks (vena contracta: $0.42 \pm 0.09 \mathrm{~cm}$ to $0.08 \pm 0.12 \mathrm{~cm} ; P<.01)$ with significant increase in the slope of end-systolic pressure-volume relationship $(1.1 \pm 0.5 \mathrm{~mm} \mathrm{Hg} / \mathrm{mL}$ to $2.9 \pm 0.7 \mathrm{~mm} \mathrm{Hg} / \mathrm{mL}$; $P<.05)$. There was a significant reduction in $\mathrm{LV}$ volumes from chronic IMR to euthanasia stage with poly-mesh compared with sham group (\%end-diastolic volume change $-20 \pm 11$ vs $15 \% \pm 16 \%, P<.01 ; \%$ end-systolic volume change $-14 \% \pm 19 \%$ vs $22 \% \pm 22 \%, P<.05$; poly-mesh vs sham group) consistent with reverse remodeling.

Conclusions: An adjustable polymer filled mesh device reduces IMR and prevents continued LV remodeling during chronic follow-up. (J Thorac Cardiovasc Surg 2018;155:1485-93)

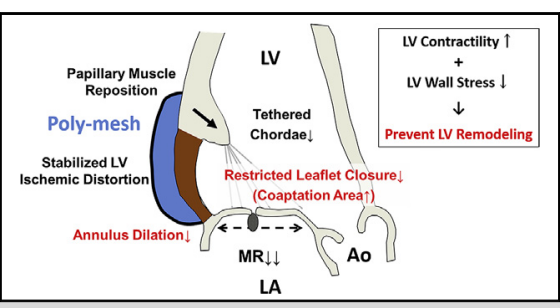

Poly-mesh device for relieving leaflet tethering and $M R$ and prevention of LV remodeling.

\section{Central Message}

This study examines the efficacy of a novel therapy for ischemic mitral regurgitation that directly relieves leaflet tethering while also preventing the progression of both $\mathrm{LV}$ and $\mathrm{LA}$ adverse remodeling

\section{Perspective}

This study demonstrates the chronic efficacy of a novel therapy for IMR that both reduces MR but also results in stabilization and repositioning of the infarcted myocardial wall. This approach offers a potential alternative for relieving tethering and IMR and prevention of progression of both LV and LA adverse remodeling, and furthermore it has potential minimally invasive applications in the beating heart

See Editorial Commentary page 1494.

\footnotetext{
From the ${ }^{\mathrm{a} C a r d i o l o g y}$ Division, Department of Medicine, and ${ }^{\mathrm{b}}$ Cardiac Surgery Division, Department of Surgery, Massachusetts General Hospital, Boston, Mass; and ${ }^{\mathrm{c}}$ Cambridge Polymer Group, Inc, Boston, Mass.

This work was supported in part by National Institutes of Health (NIH)/The National Heart, Lung, and Blood Institute (NHLBI) R01 HL092101 and by EchoInvestigator Award from American Society of Echocardiography (to Dr Hung), and by grants NIH/NHLBI R01 038176 (to Dr Levine), and grants Overseas Research Fellowship Award from Japanese Society of Echocardiography and Research Fellowship Award from Uehara Memorial Foundation, Tokyo, Japan (to Dr Kataoka).

Received for publication April 5, 2017; revisions received Oct 14, 2017; accepted for publication Nov 5, 2017; available ahead of print Dec 15, 2017.

Address for reprints: Judy Hung, MD, Massachusetts General Hospital, 55 Fruit St, Blake 256, Boston, MA 02114 (E-mail: jhung@mgh.harvard.edu). $0022-5223 / \$ 36.00$

Copyright (c) 2017 by The American Association for Thoracic Surgery https://doi.org/10.1016/j.jtcvs.2017.11.006
}

Ischemic mitral regurgitation (IMR) is an important consequence of myocardial infarction (MI) and associated with increased mortality and morbidity. IMR results from ischemic left ventricular (LV) distortion, which displaces the papillary muscles (PMs) and tethers the mitral valve (MV) leaflets apically, restricting leaflets closure and dilating the mitral annulus. ${ }^{1}$ Therapy for IMR remains controversial and challenging. ${ }^{2,3}$ Mitral ring annuloplasty, a popular surgical therapy for IMR, is associated with a

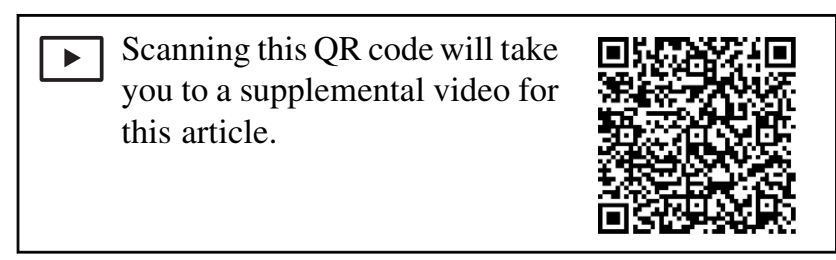




$\begin{array}{ll}\text { Abbreviations and Acronyms } \\ \text { 2D } & =\text {-dimensional } \\ \text { 3D } & =\text {-dimensional } \\ \mathrm{dP} / \mathrm{dt} & =\text { rate of rise of left ventricular pressure } \\ \mathrm{EDV} & =\text { end-diastolic volume } \\ \mathrm{Emax} & =\text { slope of end-systolic pressure-volume } \\ & \text { relationship } \\ \mathrm{ESV} & =\text { end-systolic volume } \\ \mathrm{GLS} & =\text { global longitudinal strain } \\ \mathrm{IMR} & =\text { ischemic mitral regurgitation } \\ \mathrm{LA} & =\text { left atrium } \\ \mathrm{LV} & =\text { left ventricular } \\ \mathrm{LVEF} & =\text { left ventricular ejection fraction } \\ \mathrm{MI} & =\text { myocardial infarction } \\ \mathrm{MR} & =\text { mitral regurgitation } \\ \mathrm{MV} & =\text { mitral valve } \\ \mathrm{PISA} & =\text { proximal isovelocity surface area } \\ \mathrm{PM} & =\text { papillary muscle } \\ \text { poly-mesh } & =\text { polymer-filled mesh } \\ \text { WMSI } & =\text { wall motion score index }\end{array}$

significant recurrence rate of IMR and has not been effective at reducing LV adverse remodeling. ${ }^{4-6}$ Mitral ring annuloplasty also does not directly address the fundamental mechanistic cause of IMR, which is LV distortion resulting in mitral leaflet tethering.

To directly address ischemic LV morphology and to prevent further LV adverse remodeling, we developed and examined the efficacy of a biocompatible polymerfilled mesh (poly-mesh) device for treatment of IMR. Our group has previously described 2 strategies to alleviate IMR: direct polymer injection into the infarcted ventricular territory to reposition the $\mathrm{PM}$ and a patch balloon device to externally remodel the infarcted ventricular segment. ${ }^{7,8}$ The poly-mesh device combines these 2 latter therapies by using biocompatible polymers that can be adjusted to optimize displacement and position while being contained within mesh for constraint of $\mathrm{LV}$ adverse remodeling. ${ }^{7,8}$ This results in a device that can be tailored to patient-specific LV and MV remodeling changes, as it can be adjusted, resized, and controlled to achieve the desired levels of reverse remodeling in an infarcted and distorted LV myocardium. We assessed this poly-mesh device initially in an acute IMR model to test proof of concept and subsequently in a chronic IMR model, as the latter is the more commonly encountered clinical situation.

\section{METHODS \\ Operation and Study Design}

Acute and chronic IMR models were produced via an established ovine model. ${ }^{7-9}$ This study was reviewed and approved by the institutional Animal Care Committee (institutional review board information: institutional protocol number; 2012N000160/2, approval date; March 14, 2013). The heart was exposed through a left thoracotomy and animals monitored with blood pressure, electrocardiogram, and oxygen saturation throughout the procedures. For acute IMR, the inferoposterior wall of the LV was infarcted by ligating the second, third left circumflex obtuse marginal branches, and posterior descending artery. Echocardiographic imaging confirmed the development of at least moderate IMR. The poly-mesh device was then attached to the surface of the infarcted LV epicardium with sutures followed by staples via a SECURESTRAP staple-gun (ETHICON LLC, Guaynabo, Puerto Rico) under echocardiographic guidance (Figure 1, left) and saline was applied directly to the surface of the device to hydrate the hydrogel, which was allowed to swell for approximately 10 minutes (Figure 1, right, and Video 1). The poly-mesh device can be adjusted intraoperatively to optimize IMR reduction by adding extra polymer granules through a 25-gauge needle.

Hemodynamic measurements were acquired with a microcatheter placed in the LV, and LV pressure was recorded along with an electrocardiogram lead on a physiological recorder (iWorx Systems Inc, Dover, $\mathrm{NH})$. Two-dimensional (2D) and 3-dimensional (3D) epicardial echocardiographic images were obtained (iE33, X3 matrix; Philips Medical Systems, Andover, Mass). Echo data acquisition was performed as described previously. ${ }^{7,8}$

Eight sheep (mean $6.9 \pm 1.0$ months, 4 males, $40.6 \pm 1.9 \mathrm{~kg}$ ) were in the acute experiments. Data were collected in 3 stages as follows: baseline, acute IMR (within 1 hour after the IMR creation), and acute polymesh (within 1 hour of attachment) (Figure 2, upper panel). For chronic IMR, after MI creation, the chest was closed, and the 10 sheep were allowed to recover. Following 8 weeks of LV remodeling, 5 sheep (mean $7.8 \pm 2.4$ month at baseline, 2 males, mean $42.0 \pm 3.3 \mathrm{~kg}$ at baseline) underwent a second thoracotomy, and poly-mesh was applied chronically for an additional 8 weeks before they were euthanized. In addition, 5 sham sheep (mean $5.4 \pm 1.3$ month at baseline, 3 males, mean $43.4 \pm 3.0 \mathrm{~kg}$ at baseline) underwent the same surgeries but did not have a poly-mesh device placed. There were no significant differences in the characteristics between the poly-mesh and sham sheep. In the chronic experiments, data were collected at baseline, chronic IMR stage (before attachment), and euthanasia stage (chronic poly-mesh) stages; (Figure 2, lower panel).

\section{Poly-Mesh Device}

The device used to create postinfarction LV myocardial displacement was a hybrid construct composed of an expandable hydrogel confined within a porous mesh (Cambridge Polymer Group, Inc, Boston, Mass). Each device was composed of either highly absorbent dehydrated polyacrylate (acute IMR models) or polyacrylamide granules (chronic IMR models) contained within 2 confining layers of a porous polyester mesh and surrounded by a thinner outer border of reinforcing polyester fabric (Figure 1). The device was intended to be delivered in a compact form (less than $1 \mathrm{~cm}$ maximum diameter) and then rapidly expand once anchored to the heart wall and hydrated with saline.

Polyacrylamide has been used successfully in tissue bulking, reconstructive applications, urinary incontinence, and soft contact lenses. ${ }^{10-12}$ Polyester such as polyethylene terephthalate, or PET, are used frequently in biomedical materials. ${ }^{13}$ Of note, the exact polymer material chosen for the mesh is not critical for this device, and other chemistries may be suitable. The hydrogel patch devices were sterilized by electron beam radiation at a dose of $32.5 \mathrm{kGy} \pm 2.5 \mathrm{kGy}$ before use in chronic IMR models. Cytotoxicity testing (per ISO 10993-5 MEM Elution Method) found a Grade 0 reactivity level for both the dehydrated polyacrylamide granules and the polyester mesh. Endotoxicity testing (per USP $<85>$ LAL kinetic-chromogenic method) found a reactivity of less than $0.975 \mathrm{EU} / \mathrm{g}$ for the polyacrylamide granules and less than $0.004 \mathrm{EU} / \mathrm{cm}^{2}$ for the polyester mesh. 
Poly-Mesh Attachment
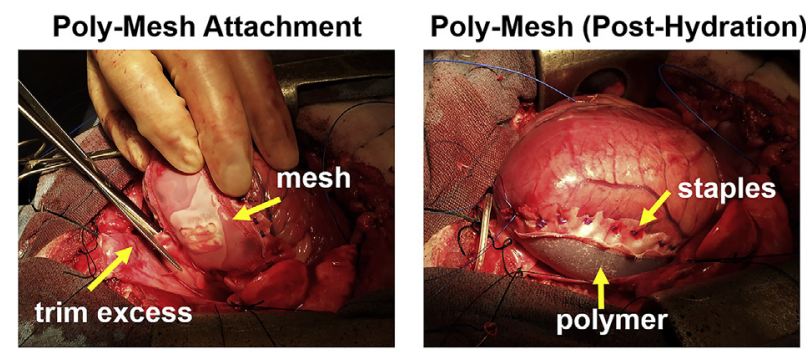

FIGURE 1. Poly-mesh device attachment during operation in acute ischemic mitral regurgitation model. Polymer granules are within mesh before hydration (left, yellow arrows). After the device attachment, the pericardial space was filled with saline, allowing the poly-mesh to swell after about 10 minutes (right, yellow arrows). After the poly-mesh swells, it is possible for extra polymer to be added through injection to adjust the left ventricular and mitral valve apparatus.

\section{IMR Assessment and MV Geometric Measures}

IMR was quantified by measuring the vena contracta width, 3D vena contracta area, and mitral regurgitation (MR) volume. ${ }^{14-16}$ MR volume was calculated using the proximal isovelocity surface area (PISA) method as $2 \pi \times \mathrm{R}_{\mathrm{PISA}}{ }^{2} \times \mathrm{V}_{\text {aliasing }} / \mathrm{V}_{\text {max }} \times$ MR regurgitant time-velocity integral, where $R_{\text {PISA }}$ was the maximal PISA radius $(\mathrm{cm}), V_{\text {aliasing }}$ was the aliasing velocity of the proximal flow convergence $(\mathrm{cm} / \mathrm{s})$, and $V_{\max }$ was the maximal velocity. A vena contracta width of $\geq 0.5 \mathrm{~cm}$ was considered moderate or greater. Mitral geometry was reconstructed from rotated images at mid-systole, when the leaflets most closely approach the annulus. Mitral annular area was measured by tracing the annular points. The PMs were traced to identify their tips by reviewing several adjacent images. Both medial and lateral tethering lengths over which the mitral leaflets and chordae are stretched between both PMs and the relatively fixed fibrous portion of the annulus were measured from posteromedial and anterolateral PM tips to the medial trigone of the aortic valve (medial junction of aortic and mitral annuli), then total length was calculated. ${ }^{1,17}$ The tenting volume of the leaflets is the volume between the leaflets and the least squares plane of the mitral annulus at mid-systole. ${ }^{18}$

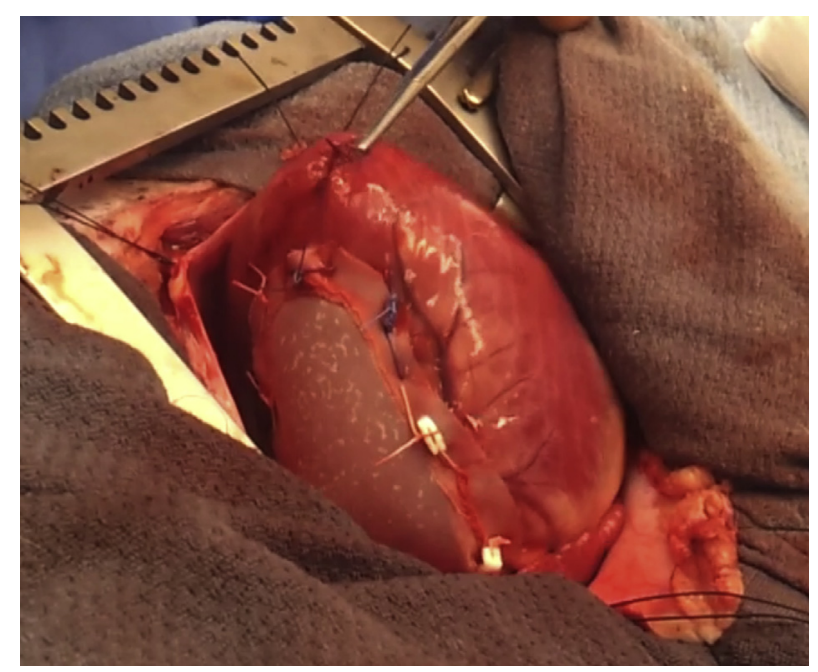

VIDEO 1. Poly-mesh device after attachment to the surface of the infarcted LV epicardium in acute IMR model. $L V$, Left ventricular; $I M R$, ischemic mitral regurgitation. Video available at: http://www.jtcvsonline. org/article/S0022-5223(17)32485-6/fulltext.
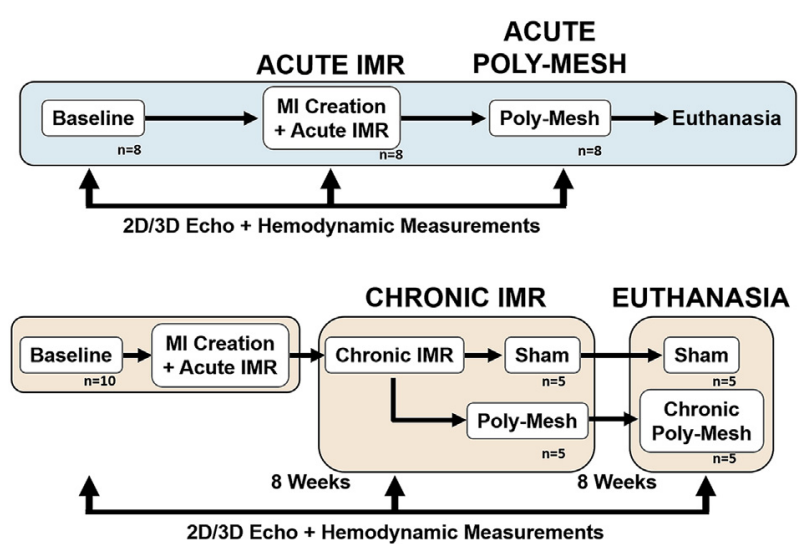

FIGURE 2. Experimental protocol using sheep models of acute (upper) and chronic IMR model (lower). IMR was produced by ligation of circumflex branches to create MI. The poly-mesh device was attached to infarcted myocardium in acute (upper) and chronic (8 weeks after MI) (lower) IMR models and compared with untreated sham sheep. All sheep were reassessed and euthanized. 2D and 3D echocardiography and hemodynamic measurements were performed at baseline, acute/chronic IMR, and acute poly-mesh/euthanasia stage. IMR, Ischemic mitral regurgitation; polymesh, polymer-filled mesh; $M I$, myocardial infarction; $2 D$, 2-dimensional; 3D, 3-dimensional; echo, echocardiography.

\section{LV and LA Measures}

LV end-diastolic volume (EDV) and end-systolic volume (ESV) were obtained by $2 \mathrm{D}$ echo, via the modified Simpson method. ${ }^{19}$ Peak systolic global longitudinal strain (GLS) in all segments was measured by the 2D speckle tracking technique (Philips QLAB, version 9.0; Philips, Andover, Mass). Pressure-volume loops were constructed from continuous tracings of LV volume, calculated with a standard algorithm, and conductance catheter (LabScribe2 version 2.382; iWorx Systems Inc). The slope of the endsystolic pressure-volume relationship (Emax) was obtained by transiently occluding the inferior vena cava with umbilical tape, thereby rapidly producing beats with varying systolic pressures and LV volumes. The endsystolic points were fitted to a linear equation; its slope (Emax) was taken as a measure of contractile state. ${ }^{20}$ The relaxation time constant (Tau) was calculated as the time for $\mathrm{LV}$ pressure to fall from peak negative rate of rise of left ventricular pressure $(\mathrm{dP} / \mathrm{dt})$ to half its value. $\mathrm{LV}$ systolic meridional wall stress was calculated by the use of the Grossman formula. ${ }^{21}$ Left atrium (LA) maximum volume at LV end-systolic phase was obtained by $2 \mathrm{D}$ echocardiography, via the biplane area-length method. ${ }^{22}$

\section{Statistical Analysis}

Based on previous data with same chronic ischemia mitral regurgitation sheep model, ${ }^{8}$ we hypothesized chronic application of poly-mesh device would result in a decrease in vena contracta width of $80 \%$, assuming a standard deviation of $0.1 \mathrm{~mm}$ and $25 \%$ decrease in LV ESV, assuming a standard deviation $10 \mathrm{~mL}$, consistent with clinical data in LV reversal remodeling. To demonstrate such changes, a sample size of 5 per group would provide $\geq 80 \%$ power with $5 \% \alpha$ error. The efficacy of polymer mesh device was tested by nonparametric repeated-measures analysis of variance (baseline, acute IMR, and acute poly-mesh in acute IMR model and baseline, chronic IMR, and euthanasia in chronic IMR model) via the Friedman test with multiple comparisons. The Mann-Whitney $U$ test was used to test for independent samples (poly-mesh group vs sham) instead of the Student $t$ test. A 2-tailed probability value of .05 was considered significant. Statistical 
Vena Contracta Width

$(n=8)$

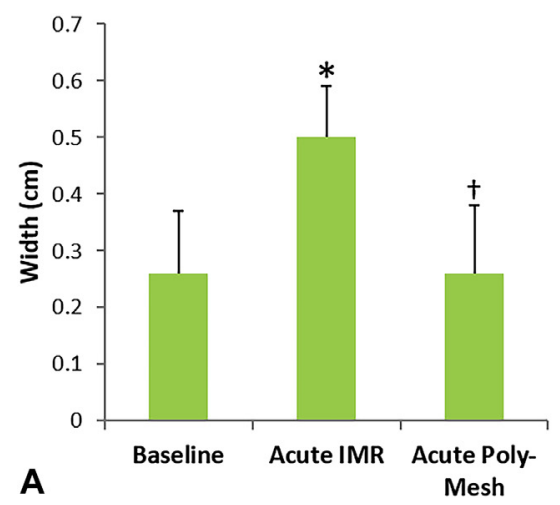

3D Vena Contracta Area

$(n=8)$

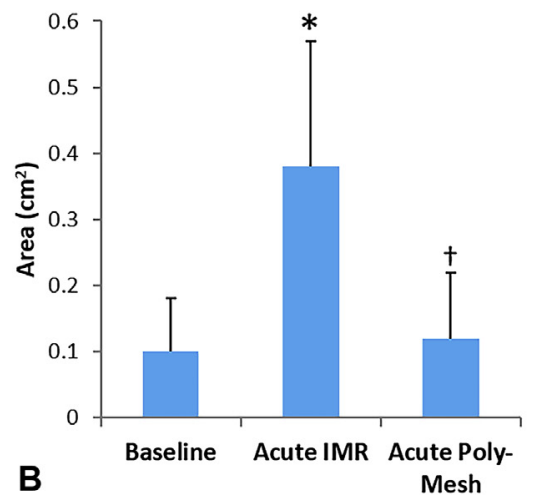

MR Volume

$(n=8)$

FIGURE 3. IMR reduction by vena contracta width $(\mathrm{A}), 3 \mathrm{D}$ vena contracta area $(\mathrm{B})$, and MR volume $(\mathrm{C})$ in the acute $\mathrm{IMR}$ model. $* P<.01$ for difference from baseline. $\dagger P<.01$ for difference from acute IMR. 3D, 3-Dimensional; $M R$, mitral regurgitation; IMR, ischemic mitral regurgitation; poly-mesh, polymer-filled mesh.

analysis was performed by with MedCalc software, ver. 12.7.1.0 (MedCalc Software, Ostend, Belgium).

\section{RESULTS}

\section{Acute IMR Model}

IMR reduction. In the acute IMR model, all sheep developed mild-to-moderate or moderate IMR after MI $(n=8)$ and underwent poly-mesh attachment onto the epicardial surface of the infarcted myocardium under echocardiographic guidance. IMR decreased to trace or mild degree in all animals after poly-mesh attachment with significantly decreased IMR parameters (Figure 3 ). The poly-mesh constructs were $4 \times 6 \mathrm{~cm}$ sized, and 2 of 8 required additional sodium polyacrylate injections for final alignment of PM location. Average mass of sodium polyacrylate in polymesh was $449.8 \pm 42.4 \mathrm{mg}$.

Change of MV geometry and $\mathrm{LV}$ parameters. The 3D echocardiography examination of MV geometry showed that there were decreases in mitral annular area, total tethering length, and tethering volume after poly-mesh attachment, consistent with favorable changes in MV geometries by poly-mesh attachment (Table 1).

TABLE 1. LV functional and 3D mitral valve geometric and hemodynamic measurements in the acute IMR model

\begin{tabular}{|c|c|c|c|c|}
\hline & Baseline & Acute IMR & Acute poly-mesh & $P$ value* \\
\hline LVEF, \% & $56.0 \pm 7.4$ & $48.8 \pm 6.0 \dagger$ & $54.6 \pm 4.7 \ddagger$ & .001 \\
\hline $\mathrm{EDV}, \mathrm{mL}$ & $61.6 \pm 10.6$ & $66.8 \pm 14.3$ & $53.7 \pm 14.4 \ddagger$ & .002 \\
\hline $\mathrm{ESV}, \mathrm{mL}$ & $27.3 \pm 7.6$ & $34.5 \pm 9.9 \S$ & $24.7 \pm 8.5 \|$ & .018 \\
\hline WMSI & $1.01 \pm 0.04$ & $1.46 \pm 0.11 \dagger$ & $1.51 \pm 0.10$ & $<.001$ \\
\hline GLS, $\%$ & $-12.7 \pm 3.0$ & $-10.1 \pm 2.1 \dagger$ & $-9.8 \pm 1.2$ & $<.001$ \\
\hline Heart rate, beats/min & $84.2 \pm 13.7$ & $82.6 \pm 13.5$ & $86.8 \pm 7.3$ & .884 \\
\hline LVSP, mm Hg & $65.2 \pm 6.9$ & $56.4 \pm 6.0$ & $57.1 \pm 5.1$ & .157 \\
\hline LVEDP, mm Hg & $11.4 \pm 4.6$ & $9.6 \pm 3.8$ & $9.3 \pm 4.9$ & .600 \\
\hline Tau, ms & $48.1 \pm 14.1$ & $51.3 \pm 19.1$ & $46.7 \pm 20.3$ & .600 \\
\hline Stiffness coefficient & $0.050 \pm 0.045$ & $0.036 \pm 0.017$ & $0.068 \pm 0.34$ & .185 \\
\hline Maximal dP/dt, $\mathrm{mm} \mathrm{Hg} / \mathrm{s}$ & $884.8 \pm 269.6$ & $683.9 \pm 105.9 \dagger$ & $968.6 \pm 140.8 \ddagger$ & .008 \\
\hline Emax, $\mathrm{mm} \mathrm{Hg} / \mathrm{mL}$ & $2.9 \pm 1.1$ & $1.6 \pm 1.0 \S$ & $1.8 \pm 0.5$ & .053 \\
\hline LV SMWS, dyne/cm² & $37.6 \pm 16.1$ & $67.6 \pm 26.9 \dagger$ & $41.0 \pm 19.5 \ddagger$ & $<.001$ \\
\hline Mitral annular area, $\mathrm{cm}^{2}$ & $8.4 \pm 0.7$ & $8.6 \pm 0.3$ & $7.5 \pm 0.5 \ddagger$ & $<.001$ \\
\hline Total tethering length, mm & $56.3 \pm 5.5$ & $59.9 \pm 3.3$ & $56.9 \pm 3.0$ & .084 \\
\hline Tethering volume, $\mathrm{cm}^{3}$ & $1.3 \pm 0.4$ & $1.4 \pm 0.3$ & $1.0 \pm 0.3 \ddagger$ & .010 \\
\hline
\end{tabular}

Values are mean \pm standard deviation. IMR, Ischemic mitral regurgitation; poly-mesh, polymer-filled mesh; $L V E F$, left ventricular ejection fraction; $E D V$, end-diastolic volume; $E S V$, end-systolic volume; WMSI, wall motion score index; $G L S$, global longitudinal strain; $L V S P$, left ventricular systolic pressure; $L V E D P$, left ventricular end-diastolic pressure; $d P / d t$, rate of rise of left ventricular pressure; Emax, slope of end-systolic pressure volume relationship; $L V S M W S$, left ventricular systolic meridional wall stress. * $P=$ Friedman test analysis of variance across 3 stages. $\dagger P<.01$ for difference from baseline. $\uparrow P<.01$ for difference from acute IMR. $\S P<.05$ for difference from baseline. $\| P<.05$ for difference from acute IMR. 


\section{Vena Contracta Width}

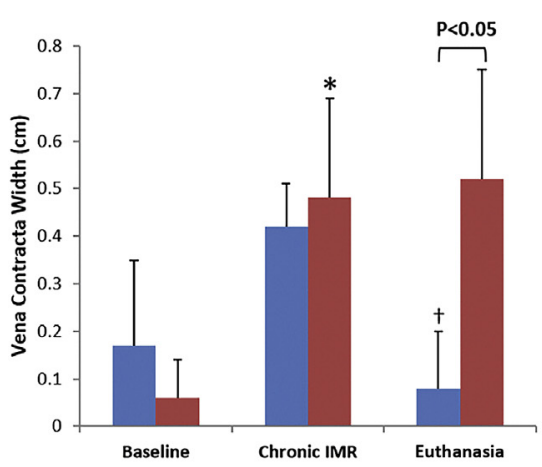

A

Doly-Mesh(n=5) $\square \operatorname{Sham}(\mathrm{n}=5)$
3D Vena Contracta Area

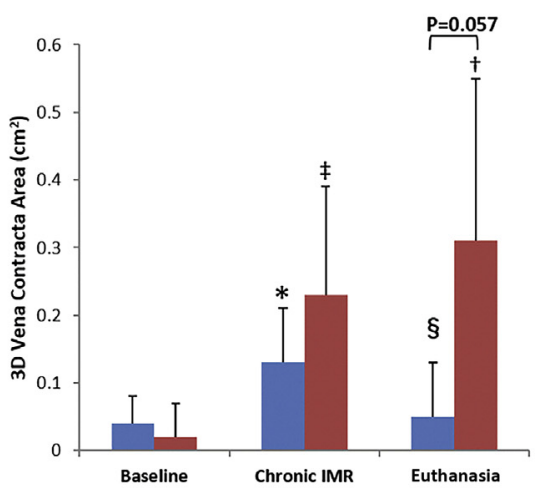

B

$\square$ Poly-Mesh $(\mathrm{n}=5) \square \operatorname{Sham}(\mathrm{n}=5)$
MR Volume

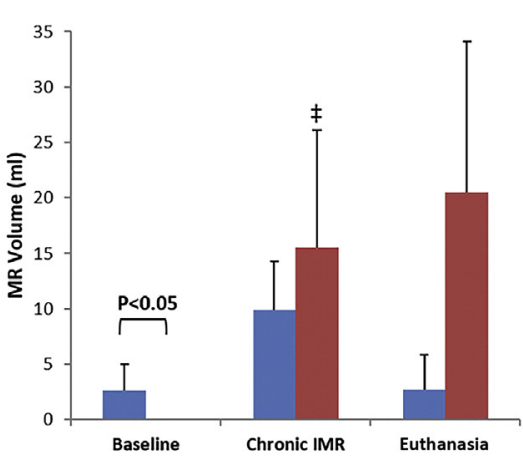

C $\quad$ Poly-Mesh(n=5) $\square \operatorname{Sham}(\mathrm{n}=5)$

FIGURE 4. Comparison of IMR reduction by vena contracta width (A), 3D vena contracta area (B), and MR volume (C) between the poly-mesh and sham groups in chronic IMR model. $* P<.01$ for difference from baseline. $\dagger P<.05$ for difference from chronic IMR. $\ddagger P<.05$ for difference from baseline. $\S P<.01$ for difference from chronic IMR. 3D, 3-Dimensional; $M R$, mitral regurgitation; IMR, ischemic mitral regurgitation; poly-mesh, polymer-filled mesh.

Left ventricular ejection fraction (LVEF) significantly increased after poly-mesh attachment. However, there were no significant changes in wall motion score index (WMSI) and GLS, which were considered LV wall functional markers. Mean LV volumes in both EDV and ESV also decreased acutely and significantly after poly-mesh attachment (EDV: $66.8 \pm 14.3 \mathrm{~mL}$ to $53.7 \pm 14.4 \mathrm{~mL}$, $P<.01$; ESV: $34.5 \pm 9.9$ to $24.7 \pm 8.5 \mathrm{~mL}, P<.05$ ) (Table 1). Hemodynamic tests could be performed on 7 of the 8 sheep. Heart rate and systolic and diastolic blood pressures were unchanged at all stages. There were also no significant changes in Tau and stiffness coefficient before and after poly-mesh attachment. However, the Emax significantly decreased after MI and increased slightly but not significantly after mesh attachment. Maximal $\mathrm{dP} / \mathrm{dt}$ increased significantly after poly-mesh attachment $(683.9 \pm 105.9 \mathrm{~mm} \mathrm{Hg} / \mathrm{s}$ to $968.6 \pm 140.8 \mathrm{~mm} \mathrm{Hg} / \mathrm{s}$, $P<.01)$. Changes were shown in LV systolic meridional wall stress, with a significant increase after MI $\left(37.6 \pm 16.1 \mathrm{dyne} / \mathrm{cm}^{2}\right.$ to $\left.67.6 \pm 26.9 \mathrm{dyne} / \mathrm{cm}^{2} ; P<.01\right)$

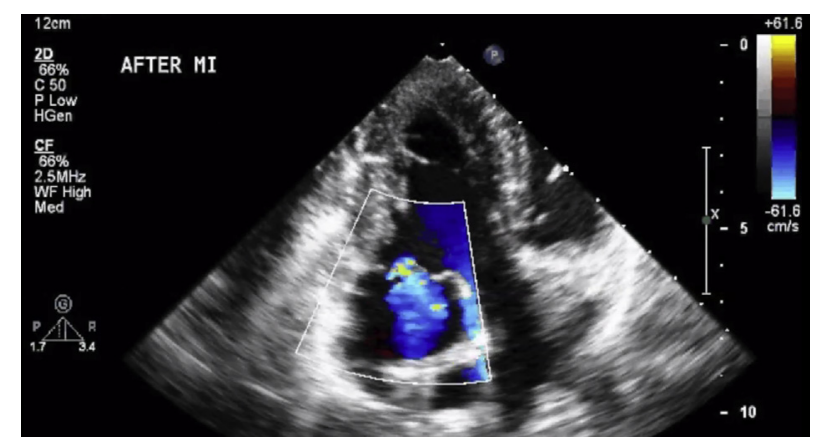

VIDEO 2. 2-Dimensional echocardiography at chronic IMR stage in chronic IMR model. IMR, Ischemic mitral regurgitation. Video available at: http://www.jtcvsonline.org/article/S0022-5223(17)32485-6/fulltext. and significant decrease after poly-mesh attachment $\left(67.6 \pm 26.9\right.$ dyne $/ \mathrm{cm}^{2}$ to $\left.41.0 \pm 19.5 \mathrm{dyne} / \mathrm{cm}^{2} ; P<.01\right)$ (Table 1).

\section{Chronic IMR Model}

IMR reduction. The poly-mesh had a final $4 \times 6 \mathrm{~cm}$ size with $1284.3 \pm 137.5 \mathrm{mg}$ mass of polyacrylamide in the mesh. This increase in starting mass (compared with the acute IMR models), was necessitated by the slightly lower final swell ratio available in the polyacrylamide relative to the polyacrylate components. In all sheep, after polymesh attachment, there was reduction in IMR which persisted over 8 weeks, and none of the sheep had recurrent important IMR (Figure 4 and Videos 2 and 3). There was no significant difference in degree of IMR at the chronic IMR stages for both poly-mesh and untreated sham sheep.

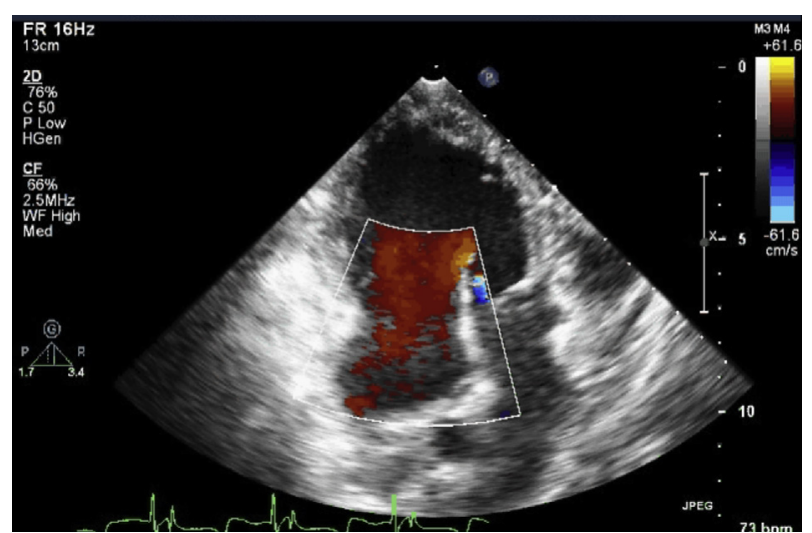

VIDEO 3. 2-Dimensional echocardiography at euthanasia stage in chronic IMR model. $L V$, Left ventricular; $I M R$, ischemic mitral regurgitation. Video available at: http://www.jtcvsonline.org/article/S0022-5223(17)32485-6/ fulltext. 
TABLE 2. LV functional and 3D mitral valve geometric measurements in the chronic IMR model

\begin{tabular}{|c|c|c|c|c|}
\hline & Baseline & Chronic IMR & Euthanasia & $P$ value* \\
\hline LVEF, \% & $55.8 \pm 8.5$ & $45.4 \pm 6.7 \dagger$ & $42.6 \pm 3.5$ & $<.001$ \\
\hline $\mathrm{EDV}, \mathrm{mL}$ & $61.5 \pm 15.6$ & $109.9 \pm 15.0$ & $88.1 \pm 17.8 \ddagger$ & .007 \\
\hline ESV, mL & $27.8 \pm 11.6$ & $60.5 \pm 13.8 \dagger$ & $50.8 \pm 11.9 \ddagger$ & $<.001$ \\
\hline WMSI & $1.03 \pm 0.06$ & $1.45 \pm 0.17 \dagger$ & $1.54 \pm 0.11 \ddagger$ & .007 \\
\hline GLS, \% & $-12.0 \pm 1.6$ & $-12.8 \pm 1.1 \S$ & $-9.4 \pm 1.1 \ddagger$ & $<.001$ \\
\hline Heart rate, beats/min & $79.8 \pm 5.4$ & $83.6 \pm 9.6$ & $86.6 \pm 12.8$ & .498 \\
\hline LVSP, mm Hg & $69.5 \pm 11.6$ & $73.3 \pm 8.7$ & $74.5 \pm 9.1$ & .849 \\
\hline LVEDP, $\mathrm{mm} \mathrm{Hg}$ & $12.9 \pm 1.7$ & $20.2 \pm 3.5 \S$ & $18.3 \pm 3.0$ & .017 \\
\hline Tau, ms & $55.1 \pm 6.7$ & $60.8 \pm 7.7$ & $73.8 \pm 14.7$ & .017 \\
\hline Stiffness coefficient & $0.015 \pm 0.006$ & $0.009 \pm 0.003$ & $0.009 \pm 0.008$ & .073 \\
\hline Emax, $\mathrm{mm} \mathrm{Hg} / \mathrm{mL}$ & $2.8 \pm 1.0$ & $1.1 \pm 0.5 \dagger$ & $2.9 \pm 0.7 \ddagger$ & .003 \\
\hline Maximal dP/dt, mm Hg/s & $885.1 \pm 30.4$ & $1020.4 \pm 168.9$ & $1044.4 \pm 117.6$ & .498 \\
\hline Mitral annular area, $\mathrm{cm}^{2}$ & $8.5 \pm 1.2$ & $9.6 \pm 1.6$ & $9.7 \pm 1.0$ & .498 \\
\hline Total tethering length, mm & $57.4 \pm 6.1$ & $65.4 \pm 3.0 \dagger$ & $63.9 \pm 6.6$ & .003 \\
\hline Tethering volume, $\mathrm{cm}^{3}$ & $1.2 \pm 0.2$ & $2.0 \pm 0.4 \S$ & $1.6 \pm 0.5$ & .017 \\
\hline
\end{tabular}

Values are mean \pm standard deviation. IMR, Ischemic mitral regurgitation; $L V E F$, left ventricular ejection fraction; $E D V$, end-diastolic volume; $E S V$, end-systolic volume; $W M S I$, wall motion score index; $G L S$, global longitudinal strain; $L V S P$, left ventricular systolic pressure; $L V E D P$, left ventricular end-diastolic pressure; Emax, slope of end-systolic pressure volume relationship; $d P / d t$, rate of rise of left ventricular pressure. $* P=$ Friedman test analysis of variance across 3 stages. $\dagger P<.01$ for difference from baseline.

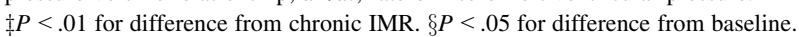

However, poly-mesh sheep had less IMR than untreated sham sheep at the time they were killed ( 8 weeks after poly-mesh attachment; vena contracta width $0.08 \pm 0.12 \mathrm{~cm}$ vs $0.52 \pm 0.23 \mathrm{~cm}, P<.05$; $3 \mathrm{D}$ vena contracta area $0.05 \pm 0.08 \mathrm{~cm}^{2}$ vs $0.31 \pm 0.24 \mathrm{~cm}^{2}$, $P=.057$ ) (Figure 4). The decrease in IMR was associated with a decrease in MV tethering length and tenting volume consistent with reduced tethering (Table 2).

Remodeling and change of $\mathbf{L V}$ and LA. Both LV EDV and ESV at the stage were reduced compared with the chronic IMR stage (EDV: $109.9 \pm 15.0 \mathrm{~mL}$ to $88.1 \pm 17.8 \mathrm{~mL}, P<.007$; ESV: $60.5 \pm 13.8 \mathrm{~mL}$ to
$50.8 \pm 11.9 \mathrm{~mL}, P<.001$ ) (Figure $5, A$ and $B$, and Table 2). EDV in all 5 sheep and ESV in 4 of the 5 sheep decreased or remained unchanged after chronic poly-mesh attachment. One sheep had a $16.6 \%$ increase in ESV. The percent increases of both EDV and ESV from chronic IMR to euthanasia stages were significantly lower than those of untreated sham sheep $(\% \mathrm{EDV}$ change $-20.2 \pm 10.6$ vs $14.8 \% \pm 15.9 \%, P<.01 ; \% \mathrm{ESV}$ change $-14.4 \pm 19.2$ vs $21.7 \% \pm 21.8 \%, P<.05$ ) (Figure $5, A$ and $B$ ). Mean LA volume also significantly decreased from the chronic IMR to the euthanasia stage in poly-mesh sheep, and there was a significant difference of LA volumes between poly-
EDV

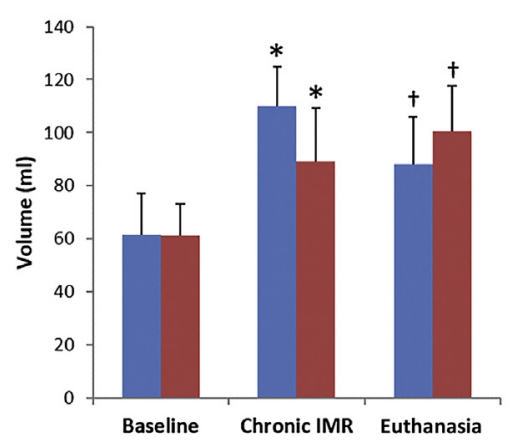

A

Poly-Mesh $(n=5)$ Sham $(n=5)$

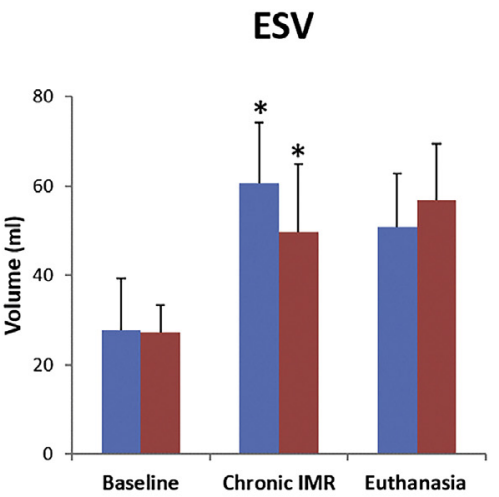

B $\square$ Poly-Mesh(n=5) $\square$ Sham(n=5)
LA volume

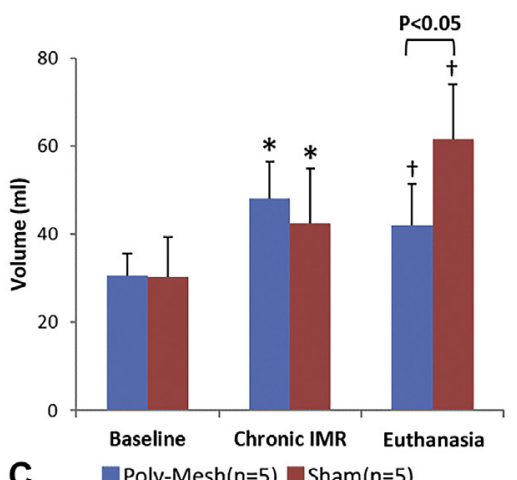

FIGURE 5. Comparison of left ventricular EDV (A) and ESV (B) and LA volume (C) at all stages between the poly-mesh and sham groups in chronic IMR model. ${ }^{*} P<.01$ for difference from baseline. $\dagger P<.01$ for difference from chronic IMR. $E D V$, End-diastolic volume; $E S V$, end-systolic volume; $L A$, left atrial; $I M R$, ischemic mitral regurgitation; poly-mesh, polymer-filled mesh. 
mesh and sham sheep $(41.9 \pm 9.5 \mathrm{~mL}$ vs $61.5 \pm 12.5 \mathrm{~mL}$, $P<.05$ ) (Figure 5, C).

LV functional change. Emax significantly increased at euthanasia stage compared with chronic IMR stage (Emax: $1.1 \pm 0.5 \mathrm{~mm} \mathrm{Hg} / \mathrm{mL}$ to $2.9 \pm 0.7 \mathrm{~mm} \mathrm{Hg} / \mathrm{mL}$, $P<.01)$ although GLS decreased slightly $(-12.8 \% \pm$ $1.1 \%$ to $-9.4 \% \pm 1.1 \%, P<.01)$ and WMSI increased $(1.45 \pm 0.17$ vs $1.54 \pm 0.11, P<.01)$. No significant changes were detected in LVEF, dP/dT, Tau, or stiffness coefficient between chronic IMR and euthanasia stages (Table 2). There was no occurrence of device-related infections, device dehiscence, or operation-related deaths during chronic IMR follow-up.

\section{DISCUSSION}

The results of this study show that an external poly-mesh device results in persistent reduction of IMR and attenuates further LV remodeling both acutely and chronically over 8 weeks of follow-up without detrimental effects on LV function.

\section{Mechanistic Implications}

These findings confirm the importance of LV adverse remodeling and distortion of the mitral apparatus in the pathogenesis of IMR. Results demonstrating efficacy in reducing IMR in an acute model highlight the importance of structural stabilization of the infarcted wall, preventing bulging and acute ischemic distortion. Structural stabilization of the infarcted wall from the poly-mesh device rather than from significant reverse remodeling of the LV is most likely the mechanism of IMR reduction in acute models, as there has been no time for the development of significant LV dilation or aneurysm. This occurred without a decrease in LV contractile function, as LVEF, WMSI, and maximal $\mathrm{dP} / \mathrm{dt}$, were either unchanged or improved after poly-mesh device attachment. There was no deterioration of indices of LV compliance with the poly-mesh device, as the device was focally applied to the abnormal, infarcted portion of the ventricle. In addition, the LV was shifted to a lower volume operating point, decreasing the compliance range at which the myocardium was working.

\section{Effects of Chronic Poly-Mesh}

Chronic poly-mesh placement was effective at reducing IMR in a chronic model. Examining a chronic IMR model was important, as this better represents the IMR seen in clinical practice, where IMR develops over weeks to months (rather than acutely during infarction) through LV adverse remodeling, resulting from LV dilation, scar, and even aneurysm formation. As in acute IMR, the chronic poly-mesh device reduced IMR, and this reduction persisted over an 8-week period. There was no decrease in LV systolic function or worsening of LV diastolic function.
Compared with untreated sham sheep, LV volumes did not increase after chronic poly-mesh attachment. The poly-mesh device resulted in reverse remodeling of the $\mathrm{LV}$, leading to decreased MV tethering. Importantly, the device showed sustained efficacy in stabilizing the LV-MV complex by attenuating further LV adverse remodeling, as compared with untreated sham sheep. This provides a key advantage over mitral ring annuloplasty, which reduces IMR by decreasing the annular area but does not stabilize the LV-MV complex nor directly reverse remodels the LV. $^{3,4,23}$ Infarction weakens myocardial mechanics with stretching of the myocardium resulting in dilation and aneurysm formation. ${ }^{24}$ The application of a poly-mesh device serves to provide mechanical support, thereby limiting stretching and expansion of infarcted myocardial walls..$^{9,25}$ This results in stabilization of the LV-MV complex and decrease in MR. Potential advantages of a poly-mesh device rather than a simple mesh device is that the poly-mesh device permits adjustment and titration of PM position to tailor for individual variations in abnormal anatomy. In addition, poly-mesh properties can be modified to mimic the physical properties of the myocardium, such as similar compressibility and tensile strength. This combination allows for mechanical support of the weakened myocardium wall while maintaining compressibility and conformational aspects. The poly-mesh device prevented progression of LA remodeling, providing an additional benefit as LA size is associated independently with increased cardiovascular risk. $^{26}$

\section{Comparison With Other Techniques}

Despite the clinical importance of IMR, its therapy remains problematic. ${ }^{2,3}$ A number of techniques have been the proposed that involve direct repositioning of the PMs or MV tethering including PM imbrication, relocation, sling placement, and chordal cutting to treat IMR. ${ }^{27-33} \mathrm{~A}$ large study examined the implantation of the Coapsys device, which decreases the internal diameter of the LV using epicardial pads connected by internal cords, for treating functional MR. ${ }^{34}$ The poly-mesh device can be applied with less-invasive procedures, as it is applied to the epicardial surface of the heart without the need for cardiopulmonary bypass and an open heart. Our group has previously described direct polymer injection into infarcted $\mathrm{PM}$ and patch balloon device as therapies to treat IMR. ${ }^{8}$ The poly-mesh device combines the advantages of these 2 latter therapies. The poly-mesh device not only reduces IMR but also limits LV remodeling. In addition, the degree of reverse remodeling or PM displacement can be adjusted by titrating the amount of polymer in the mesh device.

\section{Clinical Implications}

Current therapy with MV ring annuloplasty has not been demonstrated to have sustained beneficial effects in survival 
or other clinical endpoints. ${ }^{35}$ There are important limitations to ring annuloplasty, including significant recurrence rate of IMR which limits its efficacy., ${ }^{5,35}$ Therapies that directly address tethering and limit LV remodeling have advantages in that they may provide a more durable repair for IMR. Our experimental studies suggest a novel approach to treating IMR in both acute and chronic models that results in stabilization and repositioning of the infarcted myocardial wall and PM with relief of LV distortion and deformation, thereby restoring normal mitral leaflet closure with reduced LV wall stress. This new approach offers a potential alternative for relieving tethering and IMR and prevention of progression of both LV and LA remodeling and furthermore has potential minimally invasive applications in the beating heart, thus minimizing surgical risks factors. The device would prevent bypass grafting. Thus, it may be an option for patients without good regional revascularization option in affected grafting territories.

\section{Study Limitations}

There are important limitations to this study. Although our study achieved success of IMR treatment in both acute and chronic models of IMR, the efficacy of the poly-mesh device may be limited in globally dilated and severely dysfunctional LV. That setting may require more extensive reverse remodeling than this localized mesh therapy provides. To select the best size of poly-mesh to individual human patients, we must carefully evaluate the infarcted LV size using imaging modalities such as cardiac magnetic resonance imaging or 3D echocardiography to determine the poly-mesh design. We analyzed the echo data blinded to stage of studies including sham animals. However, there was possibility the echo reviewer might have interpreted existence of the mesh device during analyses. Finally, we only assessed chronic efficacy for 8 weeks after device placement, and more long-term follow-up is needed to assess durability of device. In this study, we did not examine histopathologic or cardiac magnetic resonance imaging data after the poly-mesh implant and hence cannot comment on LV fibrosis and scarring in this model.

\section{CONCLUSIONS}

The polymer-filled mesh device provides a novel approach to IMR, stabilizing ischemic LV remodeling and reducing mitral leaflet tethering. It is an adjustable approach to reduce IMR, resulting in persistent reduction of IMR and preventing continued LV remodeling.

\section{Conflict of Interest Statement}

Dr Braithwaite and Mr Kozak are employees of Cambridge Polymer Group Inc. All other authors have nothing to disclose with regard to commercial support.

\section{References}

1. Otsuji Y, Handschumacher MD, Schwammenthal E, Jiang L, Song JK Guerrero JL, et al. Insights from three-dimensional echocardiography into the mechanism of functional mitral regurgitation: direct in vivo demonstration of altered leaflet tethering geometry. Circulation. 1997;96:1999-2008.

2. Guy TS, Moainie SL, Gorman JH III, Jackson BM, Plappert T, Enomoto Y, et al Prevention of ischemic mitral regurgitation does not influence the outcome of remodeling after posterolateral myocardial infarction. J Am Coll Cardiol. 2004;43: 377-83.

3. Hung J, Papakostas L, Tahta SA, Hardy BG, Bollen BA, Duran CM, et al. Mechanism of recurrent ischemic mitral regurgitation after annuloplasty: continued LV remodeling as a moving target. Circulation. 2004;110:II85-90.

4. Acker MA, Parides MK, Perrault LP, Moskowitz AJ, Gelijns AC, Voisine P, et al Mitral-valve repair versus replacement for severe ischemic mitral regurgitation. N Engl J Med. 2014;370:23-32.

5. Smith PK, Puskas JD, Ascheim DD, Voisine P, Gelijns AC, Moskowitz AJ, et al. Surgical treatment of moderate ischemic mitral regurgitation. $N$ Engl J Med. 2014:371:2178-88.

6. Wijdh-den Hamer IJ, Bouma W, Lai EK, Levack MM, Shang EK, Pouch AM, et al. The value of preoperative 3-dimensional over 2-dimensional valve analysis in predicting recurrent ischemic mitral regurgitation after mitral annuloplasty. $J$ Thorac Cardiovasc Surg. 2016;152:847-59.

7. Hung J, Guerrero JL, Handschumacher MD, Supple G, Sullivan S, Levine RA. Reverse ventricular remodeling reduces ischemic mitral regurgitation: echo-guided device application in the beating heart. Circulation. 2002;106: 2594-600.

8. Zeng X, Zou L, Levine RA, Guerrero JL, Handschumacher MD, Sullivan SM, et al. Efficacy of polymer injection for ischemic mitral regurgitation: persistent reduction of mitral regurgitation and attenuation of left ventricular remodeling. JACC Cardiovasc Interv. 2015;8:355-63.

9. Hung J, Chaput M, Guerrero JL, Handschumacher MD, Papakostas L, Sullivan S, et al. Persistent reduction of ischemic mitral regurgitation by papillary muscle repositioning: structural stabilization of the papillary muscle-ventricular wall complex. Circulation. 2007;116:I259-63.

10. Jones D. Injectable Fillers. Chichester (UK): Wiley-Blackwell; 2010:182.

11. Lose G, Mouritsen L, Nielsen JB. A new bulking agent (polyacrylamide hydrogel) for treating stress urinary incontinence in women. BJU Int. 2006;98:100-4.

12. Bulking Agents for the Treatment of Stress Urinary Incontinence in Females. Available at: http://clinicaltrials.gov/ct2/show/study/NCT00629083. Accessed July 6, 2017.

13. Davis JR. Handbook of Materials for Medical Devices. Materials Park, $\mathrm{OH}$ ASM International; 2003:341.

14. Zoghbi WA, Enriquez-Sarano M, Foster E, Grayburn PA, Kraft CD, Levine RA et al. Recommendations for evaluation of the severity of native valvular regurgitation with two-dimensional and Doppler echocardiography. J Am Soc Echocardiogr. 2003;16:777-802.

15. Mele D, Vandervoort P, Palacios I, Rivera JM, Dinsmore RE, Schwammenthal E, et al. Proximal jet size by Doppler color flow mapping predicts severity of mitral regurgitation. Clinical studies. Circulation. 1995;91:746-54.

16. Zeng X, Levine RA, Hua L, Morris EL, Kang Y, Flaherty M, et al. Diagnostic value of vena contracta area in the quantification of mitral regurgitation severity by color Doppler 3D echocardiography. Circ Cardiovasc Imaging. 2011;4:506-13.

17. Handschumacher MD, Lethor JP, Siu SC, Mele D, Rivera JM, Picard MH, et al. A new integrated system for three-dimensional echocardiographic reconstruction: development and validation for ventricular volume with application in human subjects. J Am Coll Cardiol. 1993;21:743-53.

18. Chaput M, Handschumacher MD, Tournoux F, Hua L, Guerrero JL, Vlahakes GJ, et al. Mitral leaflet adaptation to ventricular remodeling: occurrence and adequacy in patients with functional mitral regurgitation. Circulation. 2008;118 $845-52$.

19. Cerqueira MD, Weissman NJ, Dilsizian V, Jacobs AK, Kaul S, Laskey WK, et al Standardized myocardial segmentation and nomenclature for tomographic imag ing of the heart. A statement for healthcare professionals from the Cardiac Imaging Committee of the Council on Clinical Cardiology of the American Heart Association. Circulation. 2002;105:539-42.

20. Suga H, Sagawa K, Shoukas AA. Load independence of the instantaneous pressure-volume ratio of the canine left ventricle and effects of epinephrine and heart rate on the ratio. Circ Res. 1973;32:314-22.

21. Grossman W, Jones D, McLaurin LP. Wall stress and patterns of hypertrophy in the human left ventricle. J Clin Invest. 1975;56:56-64. 
22. Lang RM, Bierig M, Devereux RB, Flachskampf FA, Foster E, Pellikka PA, et al. Recommendations for chamber quantification. Eur J Echocardiogr. 2006;7:79-108.

23. Kron IL, Hung J, Overbey JR, Bouchard D, Gelijns AC, Moskowitz AJ, et al. Predicting recurrent mitral regurgitation after mitral valve repair for severe ischemic mitral regurgitation. J Thorac Cardiovasc Surg. 2015;149:752-61.

24. Moainie SL, Gorman JH III, Guy TS, Bowen FW III, Jackson BM, Plappert T, et al. An ovine model of postinfarction dilated cardiomyopathy. Ann Thorac Surg. 2002;74:753-60.

25. Moainie SL, Guy TS, Gorman JH III, Plappert T, Jackson BM, St JohnSutton MG, et al. Infarct restraint attenuates remodeling and reduces chronic ischemic mitral regurgitation after postero-lateral infarction. Ann Thorac Surg. 2002; 74:444-9.

26. Tsang TS, Abhayaratna WP, Barnes ME, Miyasaka Y, Gersh BJ, Bailey KR, et al. Prediction of cardiovascular outcomes with left atrial size: is volume superior to area or diameter? J Am Coll Cardiol. 2006;47:1018-23.

27. Menicanti L, Di Donato M, Frigiola A, Buckberg G, Santambrogio C, Ranucci M, et al. Ischemic mitral regurgitation: intraventricular papillary muscle imbrication without mitral ring during left ventricular restoration. J Thorac Cardiovasc Surg. 2002;123:1041-50.

28. Kron IL, Green GR, Cope JT. Surgical relocation of the posterior papillary muscle in chronic ischemic mitral regurgitation. Ann Thorac Surg. 2002;74:600-1.

29. Hvass U, Tapia M, Baron F, Pouzet B, Shafy A. Papillary muscle sling: a new functional approach to mitral repair in patients with ischemic left ventricular dysfunction and functional mitral regurgitation. Ann Thorac Surg. 2003;75:809-11.
30. Messas E, Guerrero JL, Handschumacher MD, Conrad C, Chow CM, Sullivan S et al. Chordal cutting: a new therapeutic approach for ischemic mitral regurgitation. Circulation. 2001;104:1958-63.

31. Hung J, Mihos C. Toward a better repair for ischemic mitral regurgitation: thinking outside the ring. J Thorac Cardiovasc Surg. 2017;154: 1256-7.

32. Obase K, Matsumaru I, Miura T, Eishi K. Echocardiographic visualization and quantification of mitral complex during mitral repair for severe functional mitral regurgitation. J Thorac Cardiovasc Surg. 2017;154 1252-5.

33. Mihos C, Santana O. Can papillary muscle interventions improve mitral valve repair durability for ischemic mitral regurgitation? J Thorac Cardiovasc Surg. 2015;150:427-8.

34. Grossi EA, Patel N, Woo YJ, Goldberg JD, Schwartz CF, Subramanian V, et al Outcomes of the RESTOR-MV Trial (Randomized Evaluation of a Surgical Treatment for Off-Pump Repair of the Mitral Valve). J Am Coll Cardiol. 2010; 56:1984-93.

35. Goldstein D, Moskowitz AJ, Gelijns AC, Ailawadi G, Parides MK, Perrault LP, et al. Two-year outcomes of surgical treatment of severe ischemic mitral regurgitation. N Engl J Med. 2016;374:344-53.

Key Words: valvular disease, polymer, left ventricular remodeling, mitral regurgitation, coronary artery disease 